\title{
Lateral resistance of mass timber shear wall connected by withdrawal-type connectors
}

\author{
Sung-Jun Pang ${ }^{1}$, Kyung-Sun Ahn' ${ }^{1}$, Seog Goo Kang ${ }^{2}$ and Jung-Kwon Oh ${ }^{3^{*}}$ (D)
}

\begin{abstract}
In this study, the lateral resistances of mass timber shear walls were investigated for seismic design. The lateral resistances were predicted by kinematic models with mechanical properties of connectors, and compared with experimental data. Four out of 7 shear wall specimens consisted of a single Ply-lam panel and withdrawal-type connectors. Three out of 7 shear wall specimens consisted of two panels made by dividing a single panel in half. The divided panels were connected by 2 or 4 connectors like a single panel before being divided. The applied vertical load was 0 , 24 , or $120 \mathrm{kN}$, and the number of connectors for connecting the Ply-lam wall-to-floor was $2 \mathrm{or} 4$. As a result, the tested data were 6.3 to $52.7 \%$ higher than the predicted value by kinematic models, and it means that the lateral resistance can be designed by the behavior of the connector, and the prediction will be safe. The effects of wall-to-wall connectors, wall-to-floor connectors and vertical loads on the shear wall were analyzed with the experimental data.
\end{abstract}

Keywords: Ply-lam, Shear wall, Connector, Lateral resistance, Kinematic model

\section{Introduction}

Mass timber panels such as cross-laminated timber (CLT), nail-laminated timber (NLT), and mass plywood panels (MPP) has been used for low-carbon design as an alternative to concrete and steel [1]. The mass timber panels can be used for floor or wall elements in the mid-rise and high-rise buildings. Hybrid CLTs using alternative materials (plywood, oriented strand board, laminated strand lumber, or hardwood) as layers of the CLT have also been reported to improve the performance and cost competitiveness [2-6]. As an example, a panel composed of solid wood and plywood lamina is called a Ply-lam (Fig. 1). Plywood panels were used in cross-layer and have advantages in terms of production cost because the price of plywood is often lower than solid wood. The dimensional stability and thermal conductivity of Ply-lam were better than typical CLT [7-10]. The structural characteristics of Ply-lam under out-of-plane bending and the

\footnotetext{
*Correspondence: jungoh@snu.ac.kr

${ }^{3}$ Research Institute of Agriculture and Life Sciences/Department of Agriculture, Forestry and Bioresources, Seoul National University, Gwanak-ro 1, Gwanak-gu, Seoul, South Korea

Full list of author information is available at the end of the article
}

withdrawal resistance of screws in Ply-lam was investigated [11, 12], but the structural performance for shear walls have not been investigated.

The mass timber panels need to be separated for transporting from factory to construction site. The separated panels are connected again by using connectors in a construction site. An experimental study is required to confirm the failure behavior and structural performance of this type of shear wall, which is made by connecting panels. Oh et al. [13] investigated the lateral behavior of cross-laminated timber shear wall (height: $2400 \mathrm{~mm}$ ) consisting of small-size CLT panel (height of panel 1: $2000 \mathrm{~mm}$, height of panel 2: $400 \mathrm{~mm}$ ) with double-spline connection. They showed that the peak load did not decrease significantly compared with the wall made of a single CLT wall. Various experimental tests on CLT shear walls [14-19] have shown that a rocking or a combination of rocking and sliding are preferable mechanisms for the seismic performance of CLT buildings [20]. Morrell et al. [21] investigated the lateral performance of MPP shear walls that were connected to various base configurations. The predominant failure of the MPP shear wall was the failure of the hold-down, like a typical CLT shear
Springer Open (c) The Author(s) 2021. This article is licensed under a Creative Commons Attribution 4.0 International License, which permits use, sharing, adaptation, distribution and reproduction in any medium or format, as long as you give appropriate credit to the original author(s) and the source, provide a link to the Creative Commons licence, and indicate if changes were made. The images or other third party material in this article are included in the article's Creative Commons licence, unless indicated otherwise in a credit line to the material. If material is not included in the article's Creative Commons licence and your intended use is not permitted by statutory regulation or exceeds the permitted use, you will need to obtain permission directly from the copyright holder. To view a copy of this licence, visit http://creativeco mmons.org/licenses/by/4.0/. 


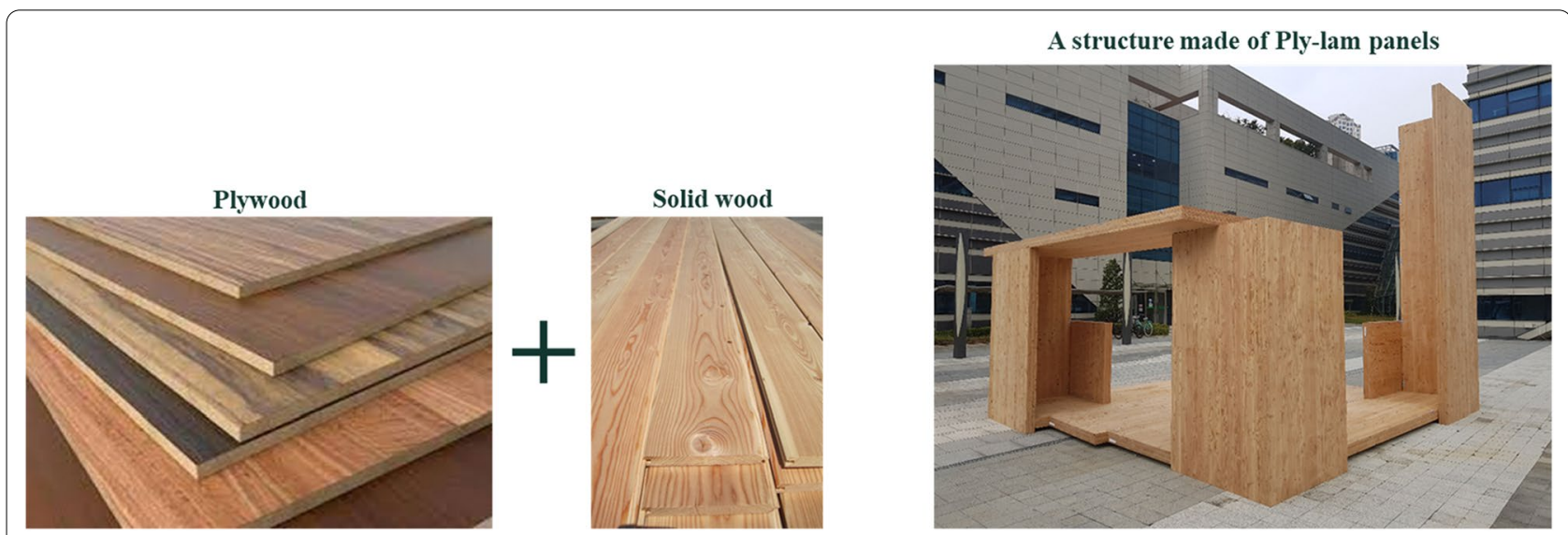

Fig. 1 Pavilion structure constructed with Ply-lam panels made of plywood and solid wood laminas

wall. Tamagnone et al. [22] investigated the influence of the floor diaphragms on the rocking behavior of shear walls. They reported that the stiffness of wall-to-floor diaphragm joints affected the overall response of the wall panel assembly. Casagrande et al. [23] and Nolet et al. [24] proposed analytical models for the behavior of a multi-panel CLT wall based on the relationship between the stiffness of the hold-down and vertical panel-to-panel joint, but the models need to be validated with experimental test. In all of the previous researches, two types of connectors, hold-downs and angle brackets, have been used to connect the wall to the floor. Hold-downs and angle brackets were assumed to resist only tension loads of the wall and to resist only lateral loads of the wall, respectively.

This study has been started to provide a reasonable design method for mass timber shear walls consisting of new hybrid CLTs, Ply-lam panels, and a Sherpa CLT connectors [25]. In the case of hold-down and angle bracket, a large number of screws $(30-70$ screws) are required to fix the connectors to panels and it is time-consuming. A withdrawal-type connector (Fig. 2) was commercialized by Sherpa Company [25] to resist both a tension load and a lateral load of the wall, and the proprietary Sherpa product uses just 10 screws to fix the Ply-lam panels. To improve the workability, the Ply-lam shear walls were constructed using the Sherpa product.

This study aimed to develop a design method for a Ply-lam shear wall connected with withdrawal-type connectors. To optimize the number of connectors in wallto-wall and wall-to-floor, several shear wall specimens were designed with various positions of connectors and validated experimentally.

\section{Materials and methods}

\section{Prediction of lateral resistance for shear wall}

The lateral load capacity $(F)$ of the shear wall was predicted by using the static equilibrium with a vertical uniformly distributed load. Three types of kinematic models were assumed based on the previously reported models for CLT shear wall consisting of hold-down [20]. First, the single-wall behavior occurs when the two panels rotate at one center of rotation (Fig. 3a). Second, the coupled-panel behavior occurs when each panel rotates at its respective point of rotation (Fig. 3b). Third, the single-coupled-panel behavior is similar to coupled-panel behavior, but the rotation point of panel 2 (B point) is uplift from the floor (Fig. 3c) [26]. From the three types of models, three lateral load capacities can be predicted with the capacity of wall-to-floor connection $\left(R_{\mathrm{p} 1, \mathrm{i}}\right.$ and $\left.R_{\mathrm{p} 2, \mathrm{i}}\right)$ and all-to-wall connection $\left(R_{\mathrm{s}}\right)$. The lateral resistance of shear wall specimens can be determined by a small value of prediction for safety.

\section{Single-wall kinematic model}

The lateral load capacity of the single-wall model is calculated by the moment equilibrium at the bottom right corner of the wall (A point in Fig. 3a) (Eq. 1). Equation 1 can be expressed as Eq. 2 for the lateral load capacity $(F)$. The tensile resistance of a connector on each panel can be written with tensile stiffness of connector $\left(K_{\mathrm{T}}\right)$, a distance from the rotation point, and a rotation angle of shear wall (Eqs. 3 and 4). The angle $(\theta)$ is identical for all of the wall-to-floor connector, and the distance between the connector and the rotation point is the distance from A point to each connector as shown in Fig. 3.

$$
\begin{aligned}
\sum M_{A_{-} \text {single }}= & \sum\left(R_{p 1, i} \times x_{p 1, i}\right)+\sum\left(R_{p 2, i} \times x_{p 2, i}\right) \\
& +\left(q_{w} \times w \times \frac{w}{2}\right)-F \times h=0,
\end{aligned}
$$




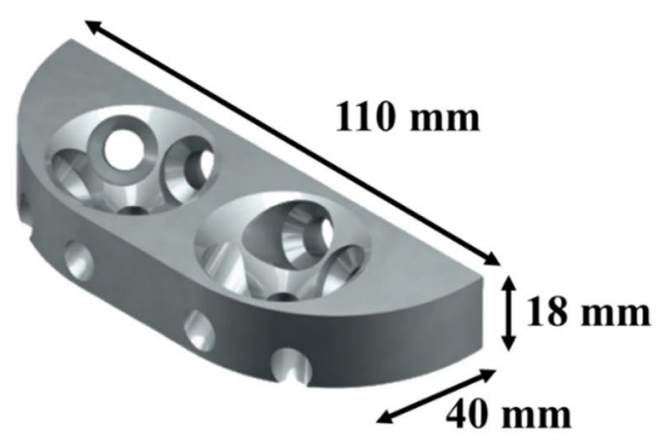

a Shape of connector
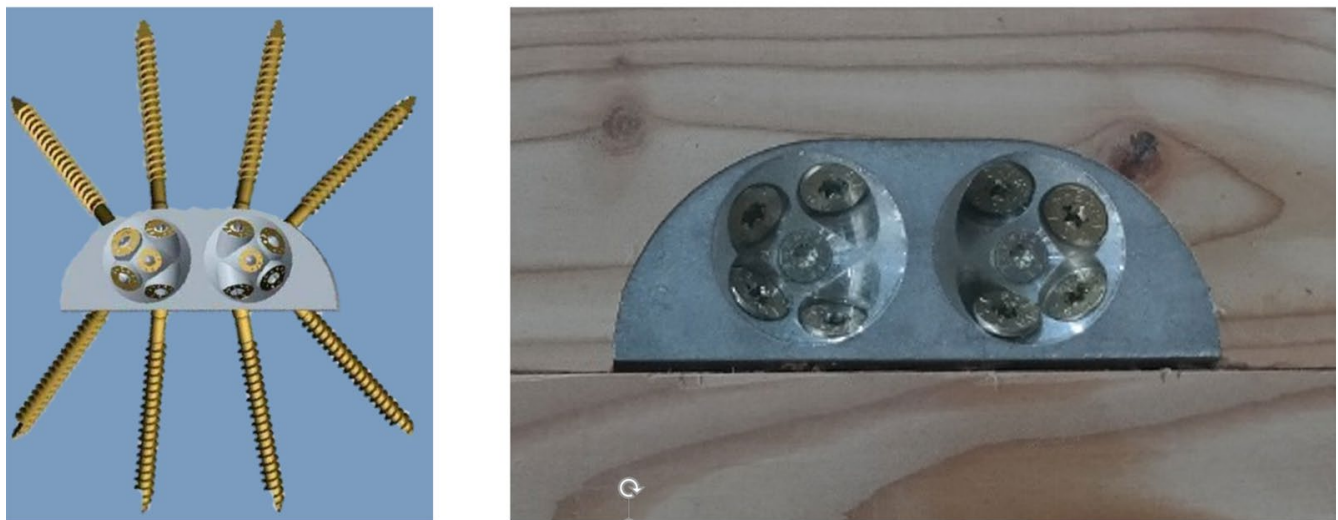

b Connector with screws

Fig. 2 Configuration of SHERPA CLT-connector [25]

where $M_{\mathrm{A} \_ \text {single }}=$ moment at the rotation point (A point in Fig. 3a) $(\mathrm{N} \mathrm{mm}), R_{\mathrm{p} 1, \mathrm{i}}=$ tensile resistance of $i$ th connector on panel $1(\mathrm{kN}), x_{\mathrm{p} 1, \mathrm{i}}=$ distance of $i$ th connector on panel 1 from rotation point $(\mathrm{mm}), R_{\mathrm{p} 2, \mathrm{i}}=$ tensile resistance of $i$ th connector on panel $2(\mathrm{kN}), x_{\mathrm{p} 2, \mathrm{i}}=$ distance of $i$ th connector on panel 2 from rotation point $(\mathrm{mm}), q_{\mathrm{w}}=$ vertical load per unit length $(\mathrm{kN} / \mathrm{m}), w=$ width of shear wall $(\mathrm{mm}), F=$ lateral resistance of shear wall $(\mathrm{kN}), h=$ height of shear wall $(\mathrm{mm})$.

$$
F_{\text {single }}=\frac{\sum\left(R_{p 1, i} \times x_{p 1, i}\right)+\sum\left(R_{p 2, i} \times x_{p 2, i}\right)+\left(q_{w} \times \frac{w^{2}}{2}\right)}{h},
$$

where $F_{\text {single }}=$ lateral resistance of shear wall by single wall kinematic model $(\mathrm{kN})$.

$$
R_{p 1, i}=K_{T} \times \delta_{p 1 . i}=K_{T} \times x_{p 1, i} \times \tan \theta,
$$

where $K_{\mathrm{T}}=$ tensile stiffness of connector $(\mathrm{kN} / \mathrm{mm}), \delta_{\mathrm{p} 1 . \mathrm{i}}$ $=$ displacement of $i$ th connector on panel $1(\mathrm{~mm}), \theta=$ rotation angel of shear wall (degree).

$$
R_{p 2, i}=K_{T} \times \delta_{p 2, i}=K_{T} \times x_{p 2, i} \times \tan \theta,
$$

where $\delta_{\mathrm{p} 2 . \mathrm{i}}=$ displacement of $i$ th connector on panel 2 $(\mathrm{mm})$.

\section{Coupled-panel kinematic model}

In the coupled-panel kinematic model, there are two rotation points, A point and B point (Fig. $3 \mathrm{~b}$ ). The lateral load capacity of the coupled-panel kinematic model is calculated by the moment equilibrium at the bottom right corner of the wall (A point) as shown in Eq. 5. The distance between the connector and the rotation point $\left(x_{\mathrm{w} 1, \mathrm{i}}\right.$ and $\left.x_{\mathrm{w} 2, \mathrm{i}}\right)$ is the distance from the rotation point of each panel (A point or Bpoint) to each connector. Thus, tensile resistance of a connector on panel 1 can be calculated by Eq. 3 like single model, but the tensile resistance of a connector on panel 2 should be calculated by Eq. 6 .

$$
\begin{aligned}
\sum M_{A_{-} \text {coupled }}= & \sum\left(R_{p 1, i} \times x_{p 1, i}\right)+\sum\left(R_{p 2, i} \times x_{p 2, i}\right) \\
& +\left(q_{w} \times w \times \frac{w}{2}\right)-(F \times h) \\
& -\left(R_{B} \times \frac{w}{2}\right)=0,
\end{aligned}
$$




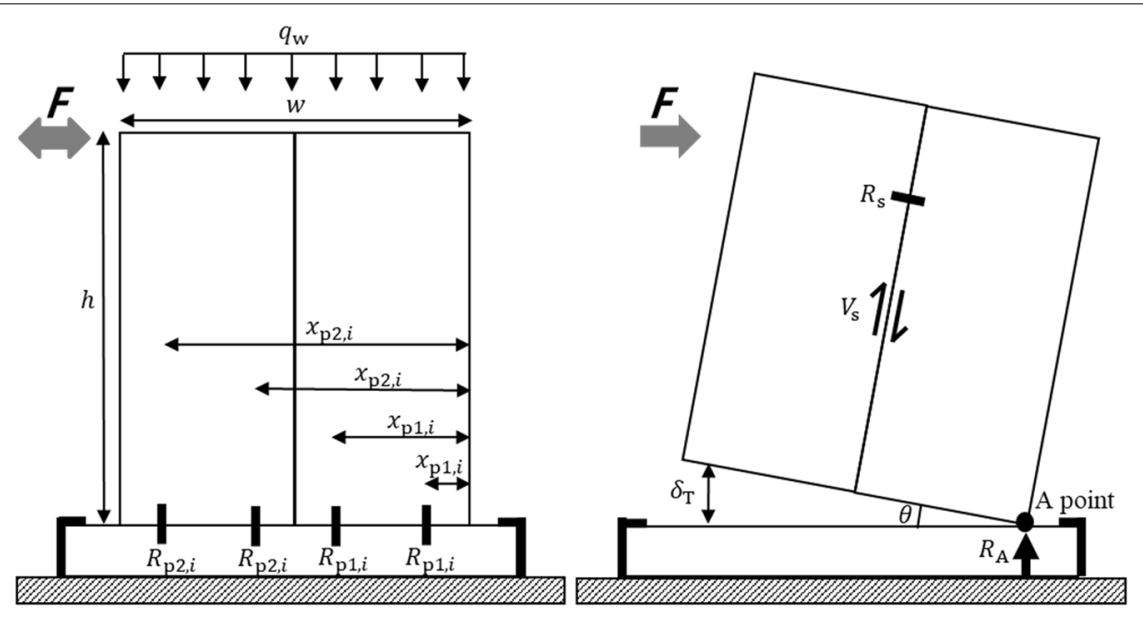

a Single-wall kinematic model
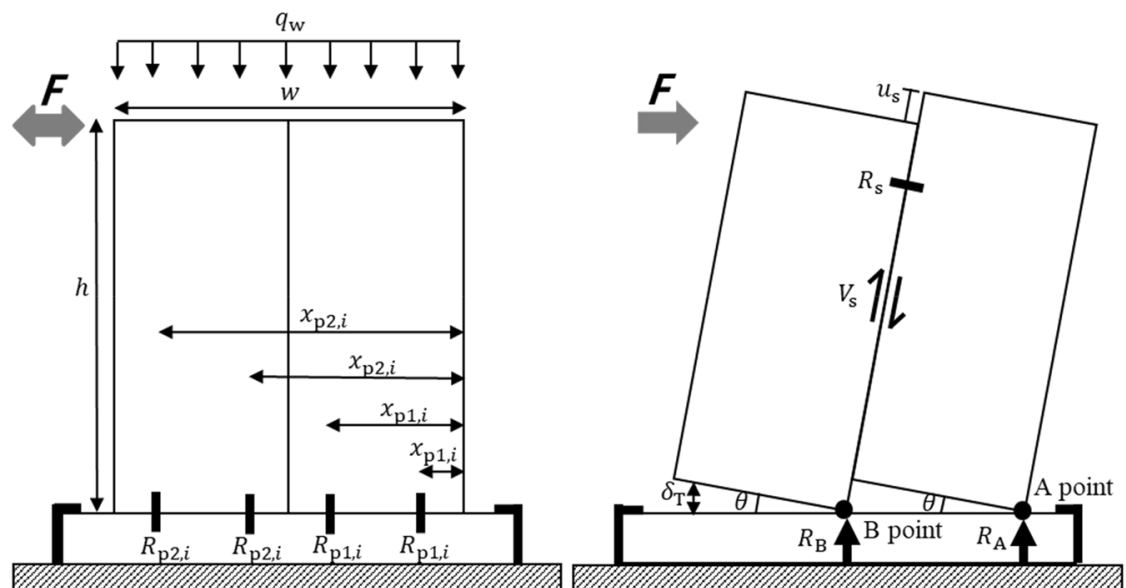

b Coupled-panel kinematic model
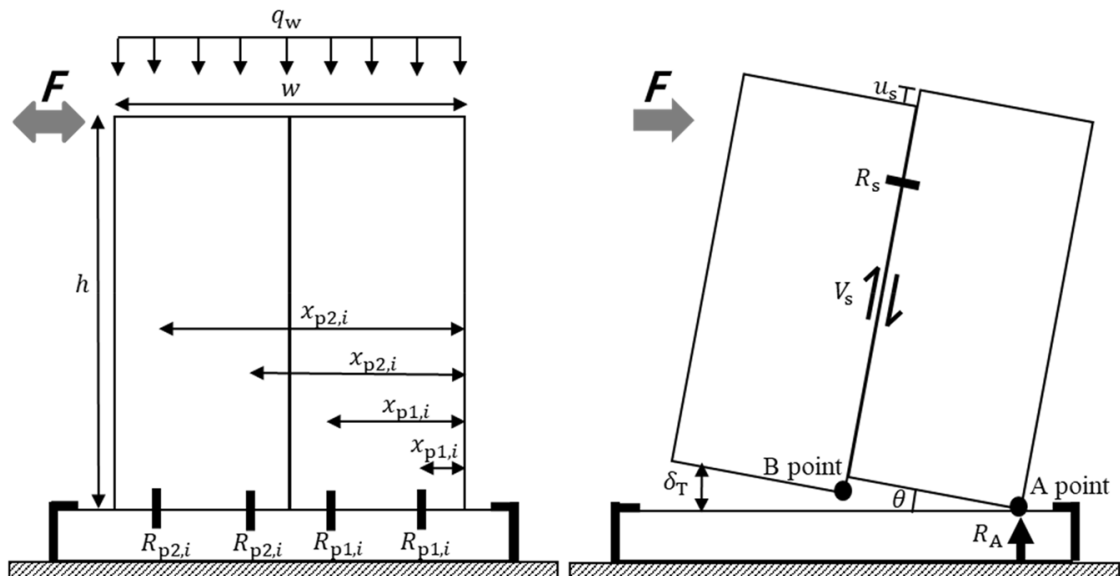

c Singe-coupled-panel kinematic model

Fig. 3 Behavior of two-panel shear wall 
where $M_{\mathrm{A} \text { coupled }}=$ moment at the rotation point (A point in Fig. $3 \mathrm{~b})$ of panel $1(\mathrm{~N} \mathrm{~mm}), R_{\mathrm{B}}=$ reaction force at the rotation point (B point in Fig. $3 \mathrm{~b})$ of panel $2(\mathrm{kN})$.

$$
R_{p 2, i}=K_{T} \times \delta_{p 2, i}=K_{T} \times\left(x_{p 2, i}-\frac{w}{2}\right) \times \tan \theta,
$$

where $K_{\mathrm{T}}=$ tensile stiffness of connector $(\mathrm{kN} / \mathrm{mm})$.

The reaction force at the rotation point of panel 2 $\left(R_{\mathrm{B}}\right)$ can be found based on the equilibrium in the vertical direction for the panel 2 (Eq. 7). Equation 7 can be expressed as Eq. 8 for $R_{\mathrm{B}}$ :

$$
\sum F_{y}=R_{B}+n \times R_{s}-\sum R_{p 2, i}-\left(q_{w} \times \frac{w}{2}\right)=0,
$$

where $F_{\mathrm{y}}=$ vertical force acting on the panel $2(\mathrm{kN}), n=$ the number of vertical connectors, $R_{\mathrm{S}}=$ shear resistance of vertical connector $(\mathrm{kN})$.

$$
R_{B}=-n \times R_{s}+\sum R_{p 2, i}+\left(q_{w} \times \frac{w}{2}\right)=0
$$

By substituting Eq. 8 into Eq. 5, the lateral load capacity $(F)$ for the coupled-panel kinematic model can be expressed as shown in Eq. 9:

$$
F_{\text {coupled }}=\frac{\sum\left(R_{p 1, i} \times x_{p 1, i}\right)+\sum\left(R_{p 2, i} \times x_{p 2, i}\right)+\left(q_{w} \times w \times \frac{w}{2}\right)+\left(n \times R_{s}-\sum R_{p 2, i}-\left(q_{w} \times \frac{w}{2}\right)\right) \times \frac{w}{2}}{h},
$$

at the bottom right corner of the wall (A point in Fig. 3c) and Eqs. 1-3 for the single-wall model can also be used for the single-coupled-panel kinematic model except for tensile resistance of the connector on panel 2 (Eq. 4). The tensile resistance of connectors on panel 2 can be calculated using Eq. 10 because the displacement of the connectors on panel 2 is reduced due to the displacement between wall panels:

$$
R_{p 2, i}=K_{T} \times\left(\delta_{p 2, i}-u_{s}\right)=K_{T} \times\left(x_{p 2, i} \times \tan \theta-u_{s}\right),
$$

where $u_{s}=$ displacement between panel 1 and panel 2 $(\mathrm{mm})$.

\section{Materials for experimental test Ply-lam panel}

Ply-lam (five layers) panels were manufactured with plywood and structural timber for use as wall and floor elements. Figure 4 shows the layup and a picture of the Ply-lam panel manufactured by Huin Co., Ltd in Korea for commercialization. Larch species (Larix kaempferi Carr.) was used for a timber layer and plywood layer. No. 3 visual grade of timber and No. 1 grade of plywood were used according to NIFoS \#2018-8 [27]. The dimen- where $F_{\text {coupled }}=$ lateral resistance of shear wall by coupled-panel kinematic model $(\mathrm{kN})$.

\section{Single-coupled-panel kinematic model}

In the single-coupled-panel kinematic model, since the rotation point of panel 2 (B point in Fig. 3 (c)) is uplift from the floor, no reaction force happens at the rotation point of panel 2. The moment equilibrium is calculated

sion of timber lamina was $25 \mathrm{~mm}$ (thickness) $\times 100 \mathrm{~mm}$ (width) $\times 2700 \mathrm{~mm}$ (length) and the moisture contents (MC) was $12 \pm 2 \%$. The size of plywood was $24 \mathrm{~mm}$ (thickness) $\times 1200 \mathrm{~mm}$ (width) $\times 2400 \mathrm{~mm}$ (length), and the MC was $7 \pm 1 \%$. Phenol-resorcinol-formaldehyde resin (PRF resin) adhesive was used to glue the flatwise surface of five layers. The glue spread was $200 \mathrm{~g} / \mathrm{m}^{2}$ and the stacked five layers were pressed under a pressure of

\begin{tabular}{|l|}
\hline $25 \mathrm{~mm}$ thick structural lumber (No.3 grade) \\
\hline $24 \mathrm{~mm}$ thick plywood (No.1 grade) \\
\hline $25 \mathrm{~mm}$ thick structural lumber (No.3 grade) \\
\hline $24 \mathrm{~mm}$ thick plywood (No.1 grade) \\
\hline $25 \mathrm{~mm}$ thick structural lumber (No.3 grade) \\
\hline
\end{tabular}

\section{$1200 \mathrm{~mm}$}

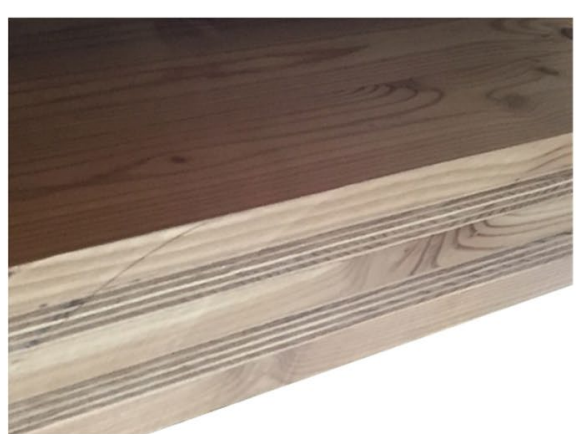

b Manufactured Ply-lam

Fig. 4 Layup and a picture of the manufactured Ply-lam panel 
$0.8 \mathrm{MPa}$ for $8 \mathrm{~h}$ using a hydraulic press. The edgewise and end surfaces of each lamina were not glued.

\section{Connector}

Withdrawal type connectors (Fig. 2) were used for connecting both wall-to-wall and wall-to-floor as shown in Fig. 5. The size of connector was $18 \times 40 \times 100 \mathrm{~mm}$, and the connector fixed a panel to another panel by using 10 screws. Out of the 10 screws, two smaller screws are installed in the middle of two caves and their dimension was $\varnothing 6.5 \times 6.5 \mathrm{~mm}$. The size of the other 8 screws was $\varnothing 8.0 \times 100 \mathrm{~mm}$. The four screws pointing down, 2 screws at the bottom of each cave in Fig. 2b, hold the other panels. The detailed specifications for the connector and screws are in ETA-18/0083 [25].

\section{Shear wall test}

\section{Shear wall specimens}

Table 1 shows the shear wall specimens made by Ply-lam panels and special CLT connectors. Seven types of shear wall specimens were prepared depending on the number

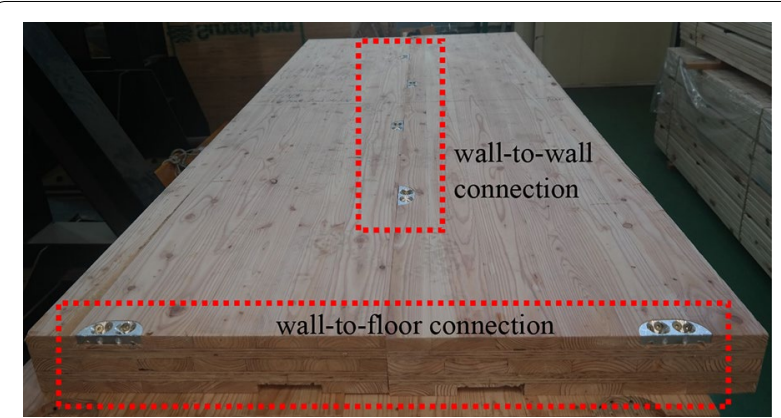

Fig. 5 Installation of withdrawal-type connectors for wall-to-wall and wall-to-floor of panels and connectors, and the vertical load. In typical platform construction, the timber walls were fixed to the timber floors. Thus, the shear walls were fixed to the Plylam floor.

The specimen ID in Table 1 indicates the wall configurations and applied vertical load. The first letter indicates the configuration for wall panel. The letter $\mathrm{S}$ means single panel used for No. 1-4 specimens in Table 1. The letter W2 and W4 used for No. 5-7 specimens, and the number means the number of panel-to-panel connectors. The second and third letter indicate the number of wall-to-floor connectors and the applied vertical load, respectively.

Figure 6 shows the configuration of shear wall specimens and the position of the linear variable displacement transducers (LVDT). Shear wall specimens in Fig. 6a-d consisted of single Ply-lam panel for wall element. Shear wall specimens in Fig. 6e-g are consisted of two Ply-lam panels for wall elements. In Fig. 6e-g, the two Ply-lam panels were made by dividing a single panel in half and they were connected by Sherpa connectors.

The size of single panel for wall (No. 1-4) was $123 \mathrm{~mm}$ (thickness) $\times 1200 \mathrm{~mm}$ (width) $\times 2700 \mathrm{~mm}$ (length) . The single panels were divided in half for coupled-wall specimens. Thus, the size of each panel for No. 5-7 was $123 \mathrm{~mm}$ (thickness) $\times 600 \mathrm{~mm}$ (width) $\times 2700 \mathrm{~mm}$ (length). As a result, the aspect ratio of the all shear wall specimens was 2.25 (height: $2.7 /$ width: 1.2 ). The vertical load applied on top of the wall was 0,24 , or $120 \mathrm{kN}$. Ply-lam floor was used for all specimens, and the size was $123 \mathrm{~mm}$ (thickness) $\times 280 \mathrm{~mm}$ (width) $\times 1600 \mathrm{~mm}$ (length).

This test was not intended for statistical comparison between groups or for deriving design values from samples, but for validating the pre-predicted shear wall

Table 1 Specimens for Ply-lam shear wall test

\begin{tabular}{|c|c|c|c|c|c|c|c|}
\hline \multirow[t]{3}{*}{ No. } & \multirow[t]{3}{*}{ Specimen ID } & \multicolumn{3}{|c|}{ Number of Ply-lam panels } & \multicolumn{2}{|c|}{ Number of connectors } & \multirow[t]{3}{*}{ Vertical load (kN) } \\
\hline & & \multicolumn{2}{|l|}{ Wall } & \multirow{2}{*}{$\begin{array}{l}\text { Floor } \\
300 \mathrm{~mm} \times 1600 \mathrm{~mm}\end{array}$} & \multirow[t]{2}{*}{ Wall to Wall } & \multirow{2}{*}{ Wall to floor } & \\
\hline & & $1200 \mathrm{~mm} \times 2700 \mathrm{~mm}$ & $600 \mathrm{~mm} \times 2700 \mathrm{~mm}$ & & & & \\
\hline 1 & $\mathrm{~S}^{\mathrm{a}} \mathrm{F}^{\mathrm{b}}{ }^{\mathrm{b}}{ }_{-} \mathrm{OkN} \mathrm{N}^{\mathrm{c}}$ & 1 & & 1 & 0 & 2 & 0 \\
\hline 2 & S_F2_24kN & 1 & & 1 & 0 & 2 & 24 \\
\hline 3 & S_F2_120kN & 1 & & 1 & 0 & 2 & 120 \\
\hline 4 & S_F4_24kN & 1 & & 1 & 0 & 4 & 24 \\
\hline 5 & W2_F2_24kN & & 2 & 1 & 2 & 2 & 24 \\
\hline 6 & W2_F4_24kN & & 2 & 1 & 2 & 4 & 24 \\
\hline 7 & W4_F4_24kN & & 2 & 1 & 4 & 4 & 24 \\
\hline
\end{tabular}

${ }^{a}$ Wall configurations: $\mathrm{S}=$ single wall, W2 = two-wall panels connected by 2 connectors, $\mathrm{W} 4=$ two-wall panels connected by 4 connectors

${ }^{b}$ The number of wall-to-floor connectors: $F 2=$ two connectors, $F 4=$ four connectors

${ }^{c}$ Applied vertical load on top of shear wall specimens 


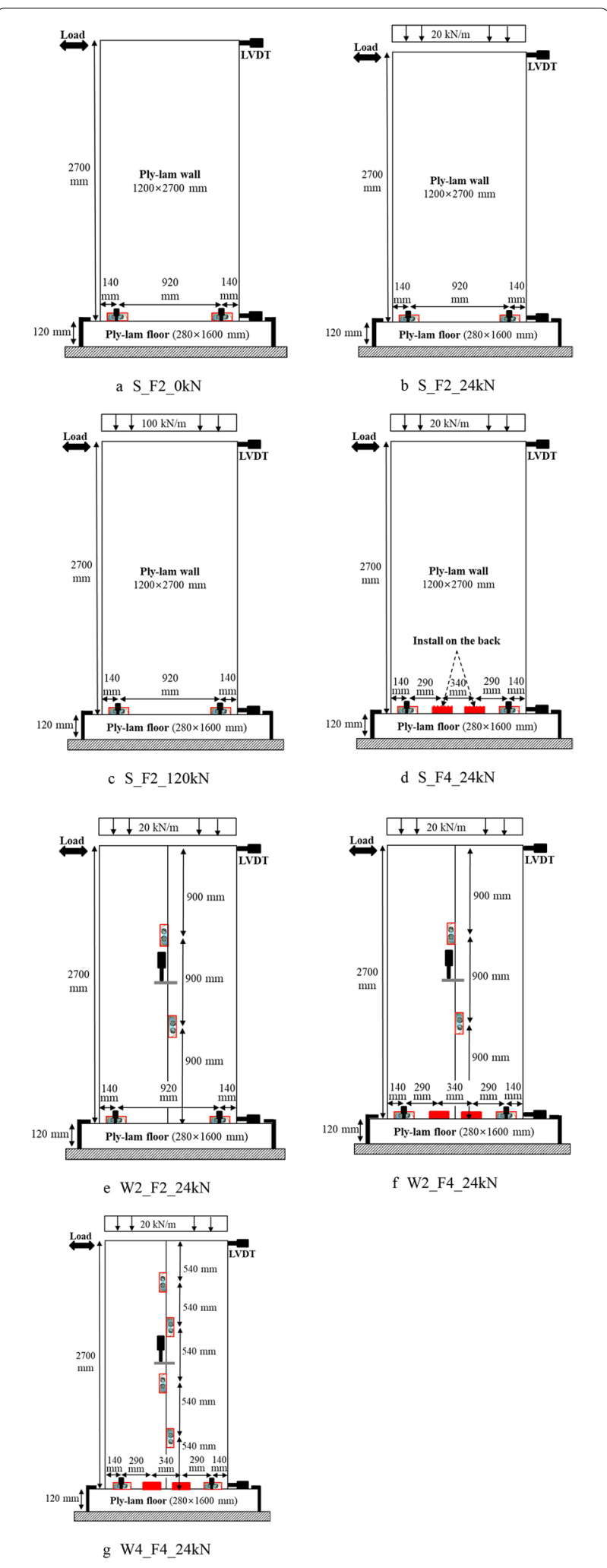

Fig. 6 Configuration of shear wall specimens

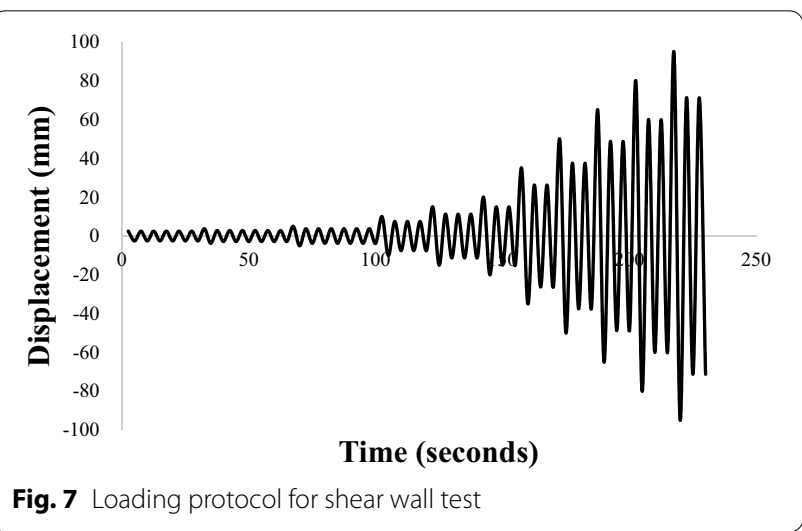

performance with the resistances of the connections that make up the shear wall. Therefore, there are no repetitions, and seven different kinds of shear wall specimens are prepared.

\section{Loading protocol and displacement}

The performance of the CLT shear wall presented in the CLT handbook was evaluated by the CUREE load protocol $[28,29]$. The CUREE load protocol in ASTM E2126 (Method C) [30] was also applied to evaluate the lateral load capacities of the shear wall specimens in this study. The displacement-controlled loading was applied for the shear wall specimens. The applied displacement history is shown in Fig. 7 and the cyclic frequency was $0.2 \mathrm{~Hz}$. The actually applied load and corresponding displacements of shear wall specimens were recorded to plot load-displacement curves. The two lateral (top and bottom) and two vertical (left and right) displacements of wall element were measured by using LVDT for all specimens as shown in Fig. 6. In case of separated wall specimens (Fig. 6e-g), a LVDT between wall panels was added to measure vertical displacement.

\section{Results and discussion}

\section{Shear wall test results}

\section{Failure mode}

Figure 8 shows the failure modes in lateral behavior of the shear wall specimens. In all the test specimens, four screws fixing the metal connector to the floor withdrew. This shows that the lateral capacity of the Ply-lam shear wall was governed by the withdrawal resistance of the screws. Bearing failure of the floor also appeared at the wall corner (Fig. 8b). Because the compressive strength in the fiber direction of wood was higher than that of wood in the direction perpendicular to the fiber direction, bearing failure of wood occurred at the floor. The bearing failure was more pronounced in the specimens with high lateral resistance, this indicates that the bearing stiffness 


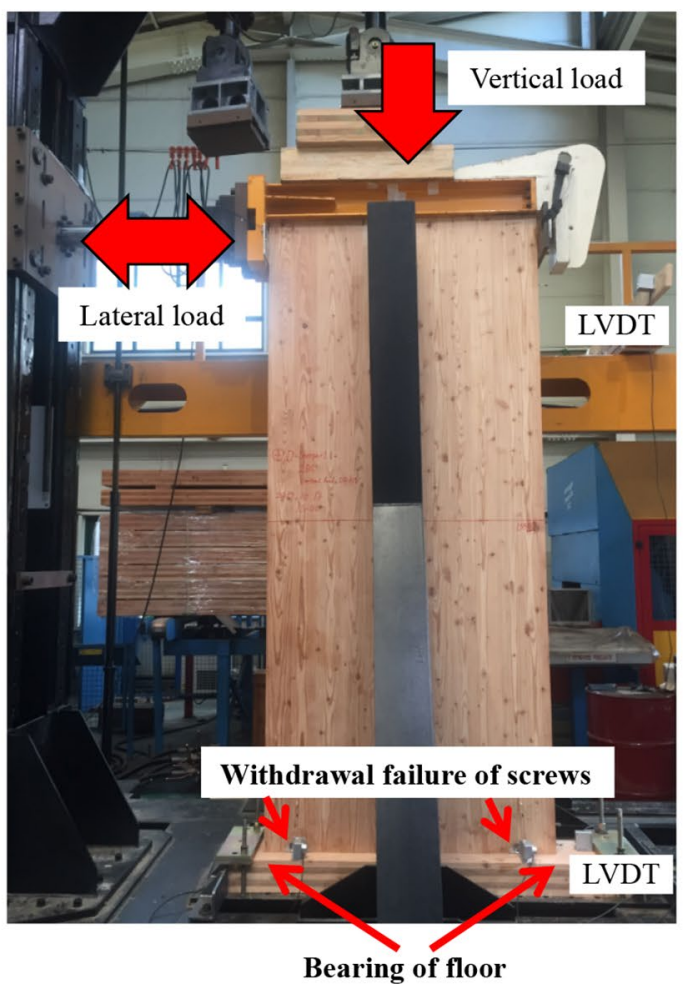

a Failure modes in lateral behavior of a shear wall specimen

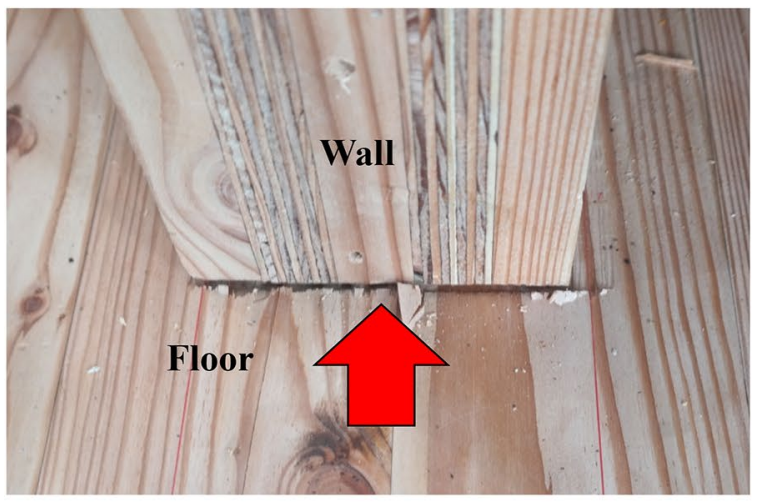

b Bearing failure of floor at the corner of wall element

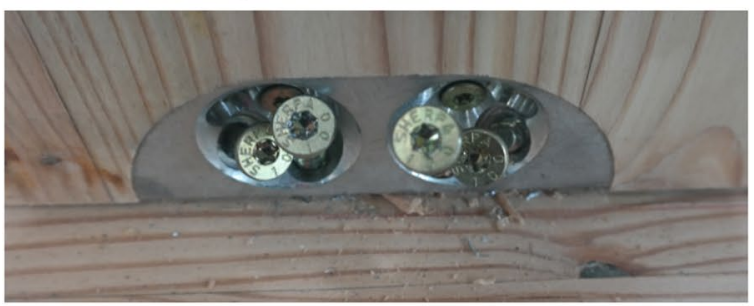

c Withdrawal failure of screws from floor element

Fig. 8 Lateral behavior and failure modes of a shear wall specimen of the floor affected the rotational stiffness of the shear wall.

\section{Effect of wall-to-floor connection}

Table 2 shows the mechanical properties of the tested Ply-lam shear wall. All of the basic mechanical properties recommended in ASTM E2126 [30] were presented. The various properties for strengths, stiffnesses, and ductilities in Table 2 were determined from the envelope curve of hysteretic load-displacement curves or the equivalent energy elastic-plastic (EEEP) curve of the tested shear walls. The envelop curve and the EEEP curves in Figs. 9, 10 and 11 were derived from the hysteretic load-displacement curves recorded during the shear wall test. The detailed methods to derive the EEEP curves are mentioned in ASTM E2126. The dots in Figs. 9, 10 show the maximum load and its displacement at each step of load protocol to derive the envelope curve of hysteretic behavior of shear wall.

The number of the connectors to fix the wall-to-floor was two or four. To investigate the effect of the wall-tofloor connectors on the lateral performance of the shear wall, specimens with different numbers of wall-to-floor connectors are compared as shown in Fig. 9. The shear strength ( $v_{\text {peak }}$, maximum load per unit specimen length) was higher when 4 connectors rather than 2 connectors were used for the wall-to-floor. In single wall panel (Fig. 9a), it was 1.8 times higher when 4 connectors $(34.8$ $\mathrm{kN} / \mathrm{m}$ for S_F4_24kN specimen) rather than 2 connectors (19.3 kN/m for S_F2_24kN specimen) were used. In two-wall panels (Fig. 9b), it was 1.5 times higher when 4 connectors (31.4 kN/m for W2_F4_24kN specimen) rather than 2 connectors $(21.4 \mathrm{kN} / \mathrm{m}$ for W2_F2_24kN specimen) were used. This is a result of an increase in uplift resistance as the number of connectors increases.

In this study, to investigate the effect of the floor panel on the shear wall, the wall panel was connected with the floor panel and the ends of the floor were fixed to the experimental equipment. If the tensile capacity of the connector between the wall panel and floor panel is strong enough to bend the floor panel, the bending stiffness and natural variability of the floor panel will affect the rigidity of the shear wall. As a result, the rigidity of the shear wall with four wall-to-floor connectors was not higher than that with two connectors. The elastic shear stiffness $\left(K_{\mathrm{e}}\right.$, a slope at $\left.0.4 P_{\text {peak }}\right)$ was higher when 2 connectors rather than 4 connectors were used for wall-tofloor. In single-wall panel, the elastic shear stiffness for 2 connectors (S_F2_24kN) and 4 connectors (S_F4_24kN) was $1,956 \mathrm{kN} / \mathrm{m}$ and $1,883 \mathrm{kN} / \mathrm{m}$, respectively. In twowall panels, the elastic shear stiffness for 2 connectors (W2_F2_24kN) and 4 connectors (W2_F4_24kN) was $2,081 \mathrm{kN} / \mathrm{m}$ and $1,532 \mathrm{kN} / \mathrm{m}$, respectively. Therefore, the 
Table 2 Mechanical properties of tested Ply-lam shear wall according to CUREE load protocol in ASTM E2126

\begin{tabular}{|c|c|c|c|c|c|c|c|c|c|c|c|c|c|c|}
\hline \multirow[t]{2}{*}{ No. } & \multirow[t]{2}{*}{ Test ID } & \multicolumn{4}{|c|}{ Strength } & \multicolumn{3}{|c|}{ Stiffness } & \multicolumn{6}{|c|}{ Ductility } \\
\hline & & $\begin{array}{l}\mathrm{V}_{\text {peak }}{ }^{\mathrm{a}} \\
(\mathrm{kN} / \mathrm{m})\end{array}$ & $\begin{array}{l}P_{\text {yield }} b \\
(k N)\end{array}$ & $\begin{array}{l}P_{\text {peak }}{ }^{c} \\
(k N)\end{array}$ & $\begin{array}{l}\mathrm{P}_{\mathrm{u}}{ }^{\mathrm{d}} \\
(\mathrm{kN})\end{array}$ & $\begin{array}{l}\mathrm{Ke}^{\mathrm{e}} \\
(\mathrm{kN} / \mathrm{m})\end{array}$ & $\begin{array}{l}G^{\prime} \text { at } 0.4 P_{\text {peak }}{ }^{f} \\
(\mathrm{kN} / \mathrm{m})\end{array}$ & $\begin{array}{l}G^{\prime} \text { at } P_{\text {peak }}{ }^{g} \\
(k N / m)\end{array}$ & $\begin{array}{l}\mathrm{D}^{\mathrm{h}} \\
(\mathrm{mm})\end{array}$ & $\begin{array}{l}D_{\text {yield }}{ }^{i} \\
(\mathrm{~mm})\end{array}$ & $\begin{array}{l}D_{\text {peak }}{ }^{j} \\
(\mathrm{~mm})\end{array}$ & $\begin{array}{l}\mathrm{D}_{\mathrm{u}}{ }^{\mathrm{k}} \\
(\mathrm{mm})\end{array}$ & $\begin{array}{l}\mathrm{A}^{\prime} \\
(\mathrm{kN} \mathrm{mm})\end{array}$ & $\mathrm{D}^{\mathrm{m}}$ \\
\hline 1 & $S^{n}{ }_{-} 2^{\circ}{ }_{-} 0 k N^{p}$ & 11.7 & 12.0 & 14.0 & 12.0 & 972.4 & 2187.9 & 1271.8 & 5.8 & 12.3 & 24.8 & 30.8 & 295.9 & 2.5 \\
\hline 2 & S_F2_24kN & 19.3 & 19.7 & 23.2 & 18.8 & 1956.0 & 4401.0 & 1737.9 & 4.7 & 10.1 & 30.0 & 51.6 & 917.5 & 5.1 \\
\hline 3 & S_F2_120kN & 37.3 & 38.3 & 44.8 & 38.0 & 6755.3 & $15,199.5$ & 2802.8 & 2.7 & 5.7 & 35.9 & 54.0 & 1961.3 & 9.5 \\
\hline 4 & S_F4_24kN & 34.8 & 34.5 & 41.7 & 33.4 & 1883.8 & 4238.6 & 2217.2 & 8.9 & 18.3 & 42.3 & 57.7 & 1672.5 & 3.2 \\
\hline 5 & W2_F2_24kN & 21.4 & 21.3 & 25.7 & 20.5 & 2081.4 & 4683.0 & 1660.7 & 4.9 & 10.2 & 34.8 & 49.4 & 942.9 & 4.8 \\
\hline 6 & W2_F4_24kN & 31.4 & 33.3 & 37.7 & 30.2 & 1532.2 & 3447.5 & 1587.6 & 9.8 & 21.7 & 53.4 & 57.5 & 1552.3 & 2.6 \\
\hline 7 & W4_F4_24kN & 29.4 & 31.5 & 35.3 & 28.2 & 1031.8 & 2321.6 & 1782.7 & 13.7 & 30.5 & 44.6 & 60.4 & 1421.3 & 2.0 \\
\hline
\end{tabular}

${ }^{a}$ Shear strength: the maximum load $\left(P_{\text {peak }}\right)$ per unit specimen length

${ }^{b}$ Yield load calculated by equivalent energy elastic-plastic (EEEP) curve

${ }^{c}$ Maximum load

${ }^{\mathrm{d}}$ Failure load

${ }^{\mathrm{e}}$ Elastic shear stiffness

${ }^{f}$ Secant shear modulus at $0.4 P_{\text {peak }}$

${ }^{g}$ Secant shear modulus at $P_{\text {peak }}$

${ }^{\mathrm{h}}$ Displacement of the top edge of the specimen at $0.4 P_{\text {peak }}$

'Yield displacement

${ }^{j}$ Maximum displacement

${ }^{\mathrm{k}}$ Ultimate displacement

'The area under envelope curve from zero to ultimate diaplacement

${ }^{m}$ Ductility ratio: the ratio of the ultimate displacement and the yield displacement of a specimen

${ }^{\mathrm{n}}$ Wall configurations: $\mathrm{S}=$ single wall, $\mathrm{W} 2=$ two-wall panels connected by 2 connectors, $\mathrm{W} 4=$ two-wall panels connected by 4 connectors

${ }^{\circ}$ The number of wall-to-floor connectors: $\mathrm{F} 2=$ two connectors, F4 = four connectors

${ }^{\mathrm{p}}$ Applied vertical load on top of shear wall specimens

experiments showed no significant difference between two and four connectors. Tension force was transferred to the floor panel enough to be bend upwards with only two connectors, and the stiffness and natural variability of the floor panel were reflected in the stiffness of the shear wall specimens.

\section{Effect of wall-to-wall connection}

To investigate the effect of wall-to-wall connectors for the lateral behavior of shear wall, shear wall specimens with the same number of wall-to-floor connectors but different number of wall-to-wall connectors were compared. Figure 10 shows the load-displacement curves depending on the number of wall-to-wall connectors. When two wall-to-floor connectors were used (Fig. 10a), the loaddisplacement curves of shear wall specimens were similar regardless of the number of wall-to-wall connectors. The shear strength and stiffness for single wall panel $\left(\mathrm{S}_{-}\right.$ F2_24kN) were $19.3 \mathrm{kN} / \mathrm{m}$ and $1,956 \mathrm{kN} / \mathrm{m}$, respectively. The shear strength and stiffness for two-wall panels with two wall-to-wall connectors (W2_F2_24kN) were 21.4 $\mathrm{kN} / \mathrm{m}$ and 2,081 $\mathrm{kN} / \mathrm{m}$, respectively. Thus, when separated wall panels were connected with two wall-to-wall connectors, the shear strength and stiffness were not decreased. Although the two-panel walls are connected with many wall-to-wall connectors, the shear behavior of the two-panel walls cannot be better than a single wall. Thus, the experimental results that the properties of the separated specimen (W2_F2_24kN) was approximately $10 \%$ higher than that of the single panel (S_F2_24kN) are considered due to the variability of the test specimens.

When four wall-to-floor connectors were used (Fig. 10b), the load-displacement curve of single wall panel ( $\mathrm{S}_{-}$ F4_24kN) and of two-wall panels with two wall-to-wall connectors (W2_F4_24kN) were also similar. When the two-wall panels were connected with four wall-to-wall connectors (W4_F4_24kN), the shear strength of shear wall specimens were $6 \%$ decreased compared to the two-wall panels connected with two wall-to-wall connectors (W2 F4_24kN). Theoretically, the shear properties of the shear wall should be increased as the number of wall-to-wall connectors increase, but the shear properties of two-panel walls cannot be better than those of a single panel. When the two-panel walls were connected with two wall-to-wall connectors (W2_F4_24kN), the shear stiffness was similar with a single panel. Thus, it is considered that the reason for 


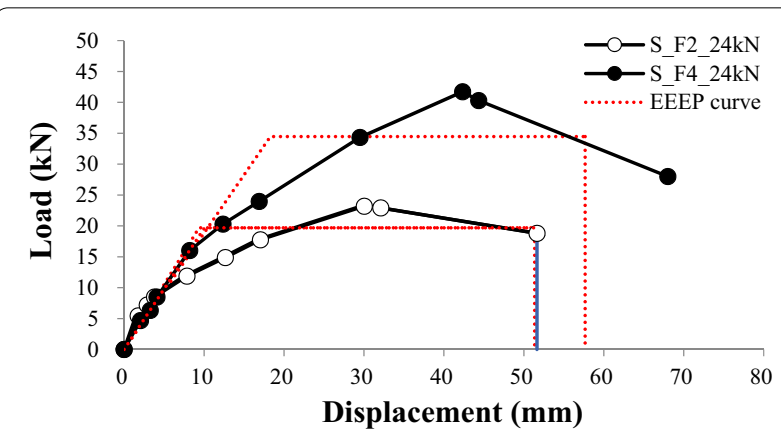

a Single wall panel

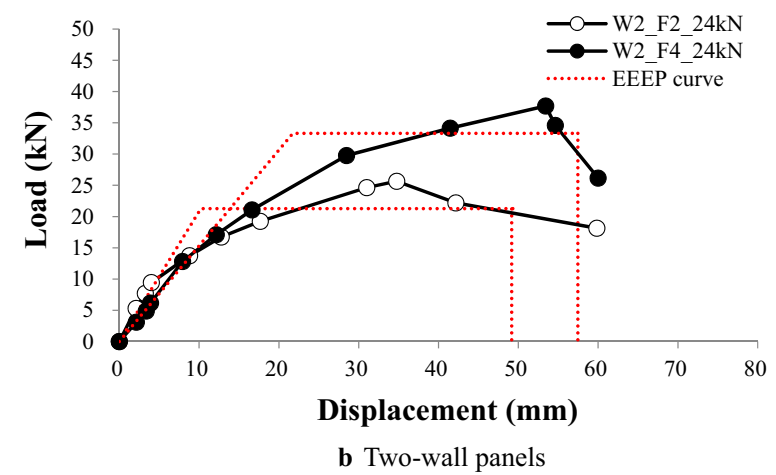

Fig. 9 Load-displacement curves depending on the number of wall-to-floor connectors

the decrease in shear stiffness of the two-panel walls with four wall-to-wall connectors (W4_F4_24kN) is the variability of the test specimens. This result indicates that even if the separated wall panels are connected using only two wall-to-wall connectors, similar performance to a singlepanel wall can be expected.

\section{Effect of vertical load}

Figure 11 shows the load-displacement curves of shear wall depending on the vertical load. All mechanical properties of shear wall increased as the vertical load increased. As the vertical load increased from 0 to $24 \mathrm{kN}$, $120 \mathrm{kN}$, the shear stiffness increased by 2.0-6.7 times and the shear strength increased by 1.7-3.2 times. These results show that the vertical load acted as a moment in the opposite direction to the lateral load. Therefore, it is possible to reduce the capacity or quantity of the wall-tofloor connectors by considering the vertical load.

\section{Validation of the prediction model}

\section{Tensile and shear properties of connector}

Table 3 shows the mechanical properties of single connector in tensile and shear test. The data were from Harrer $\mathrm{GmbH} /$ Frohnleiten (HBF) report [31]. The tensile and shear test of connectors with Ply-lam was tested

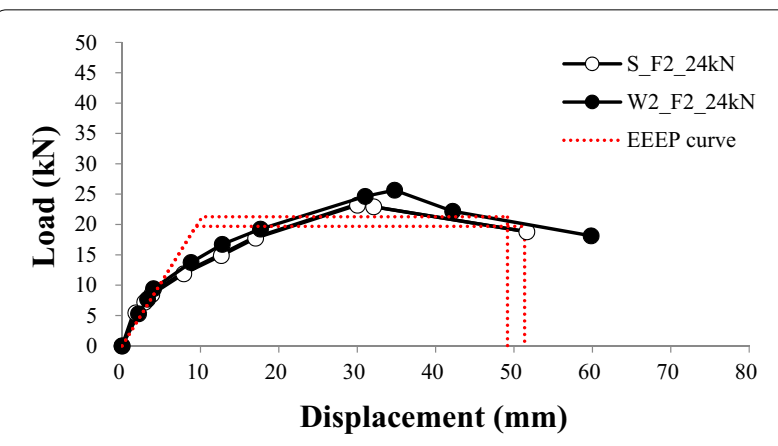

a Two connectors for wall-to-floor

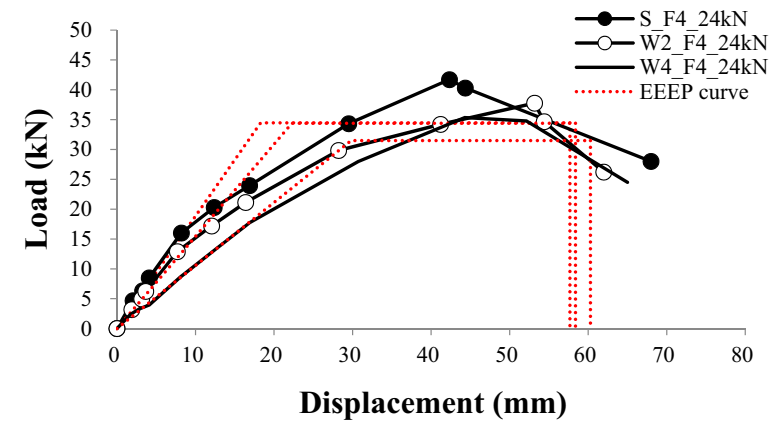

b Four connectors for wall-to-floor

Fig. 10 Load-displacement curves depending on the number of wall-to-wall connectors

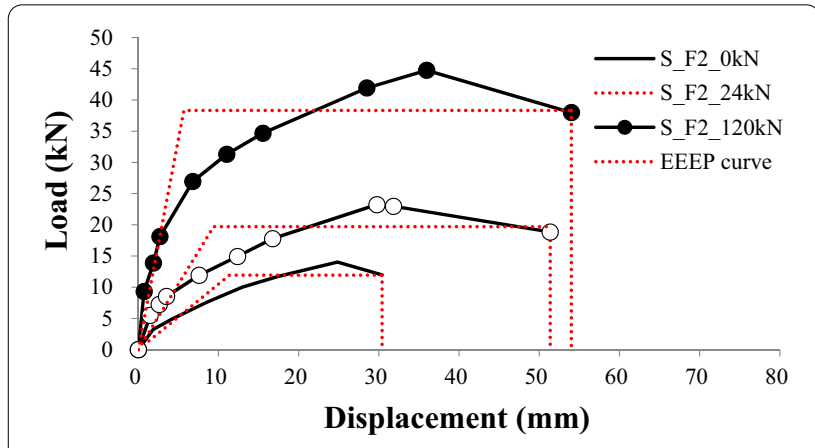

Fig. 11 Load-displacement curves depending on the vertical load

Table 3 Mechanical properties for single connector with Ply-lam

\begin{tabular}{llll}
\hline Property $^{\mathrm{a}}$ & \multicolumn{2}{l}{ Resistance $(\mathrm{kN})$} & \multicolumn{2}{c}{$\begin{array}{c}\text { Stiffness } \\
\end{array}$} & Mean value & Char. value $^{\mathrm{b}}$ & $(\mathrm{N} / \mathrm{mm})$ \\
\hline Tensile test & $43.50(17 \mathrm{~mm})^{\mathrm{c}}$ & 35.40 & 12,058 \\
Shear test & $39.50(15 \mathrm{~mm})$ & 34.10 & 8,349 \\
\hline
\end{tabular}

${ }^{a}$ The data were from Harrer GmbH/Frohnleiten (HBF) report [31]

${ }^{\text {b }}$ Characteristic value: low 5 th percentile value

${ }^{c}$ Displacement at the maximum load 
and determined according to EN 26,891 [32]. The maximum resistance in tensile test was $43.5 \mathrm{kN}$ at $17 \mathrm{~mm}$ displacement and the characteristic value (lower $5^{\text {th }}$ percentile value) according to EN 14,358 [33] was $35.4 \mathrm{kN}$. The maximum resistance in shear test was $39.5 \mathrm{kN}$ at $15 \mathrm{~mm}$ displacement and the characteristic value according to EN 14,358 was $34.1 \mathrm{kN}$. The tensile and shear stiffness of connector was calculated from the slope of a line between 10 and $40 \%$ of the maximum load.

Figure 12 shows the idealized elastic-plastic curves of connector from Table 3 to predict the lateral resistance of shear wall. The tensile and resistance of connector reached the characteristic value at $2.9 \mathrm{~mm}$ and $4.1 \mathrm{~mm}$ displacement, respectively. After the characteristic load is reached, the characteristic load is maintained up to the maximum displacement at which the connector was failure.

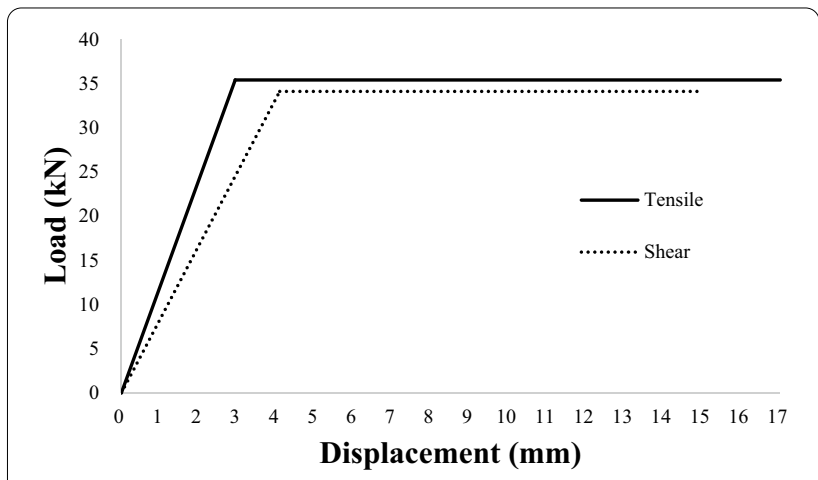

Fig. 12 Load-displacement curves of connectors
Comparisons of predicted value with experimental data

Table 4 shows the predicted lateral resistances of shear wall specimens by three different models. The lateral resistance of shear wall was determined when the rotation angle of shear wall was reached the maximum angle, which was when the wall-to-floor connector at the position furthest from the rotation point reached its maximum displacement and failed. When the furthest wall-to-floor connector reached the maximum displacement, $17 \mathrm{~mm}$, the maximum rotation angle $\left(\tan \theta_{\text {max _single }}\right)$ in single-wall kinematic model was 0.016 (Eq. 11) and lateral displacement on top of the shear wall was $43.2 \mathrm{~mm}(0.016 \times 2700 \mathrm{~mm})$. The maximum rotation angle $\left(\tan \theta_{\text {max_coupled }}\right)$ in coupled-panel model was 0.037 (Eq. 12) and lateral displacement on top of the shear wall was and $99.8 \mathrm{~mm}(0.037 \times 2700 \mathrm{~mm})$. The maximum rotation angle $\left(\tan \theta_{\text {max_single-coupled }}\right)$ in single-coupled-panel model was 0.039 (Eq. 13) and lateral displacement on top of the shear wall was and $106.7 \mathrm{~mm}(0.039 \times 2700 \mathrm{~mm})$.

$$
\tan \theta_{\text {max_single }}=\frac{\Delta h_{\text {max_single }}}{h}=\frac{\delta_{T_{-} \max }}{x_{p 2, \text { furthest }}}=\frac{17}{1060} \approx 0.016,
$$

where $\tan \theta_{\text {max _single }}=$ maximum rotation angle of shear wall in single-wall kinematic model, $\Delta h_{\text {max_single }}=$ lateral displacement on top of shear wall in single-wall kinematic model $(\mathrm{mm}), \delta_{\mathrm{T} \max }=$ maximum displacement of wall-to-floor connector $(\mathrm{mm}), x_{\mathrm{p} 2 \text {,furthest }}=$ distance of furthest connector on panel 2 from rotation point $(\mathrm{mm})$.

Table 4 Lateral resistances by experimental test and by prediction model

\begin{tabular}{|c|c|c|c|c|c|c|c|}
\hline \multirow[t]{2}{*}{ No. } & \multirow[t]{2}{*}{ Tested data (kN) } & \multicolumn{2}{|c|}{ Single-wall model } & \multicolumn{2}{|c|}{ Coupled-panel model } & \multicolumn{2}{|c|}{ Single-coupled-panel model } \\
\hline & & $\begin{array}{l}\text { Predicted } \\
\text { value }^{\mathrm{a}}(\mathrm{kN})\end{array}$ & Accuracy ${ }^{b}(\%)$ & $\begin{array}{l}\text { Predicted } \\
\text { value }^{c}(\mathrm{kN})\end{array}$ & Accuracy (\%) & $\begin{array}{l}\text { Predicted } \\
\text { value }^{d}(k N)\end{array}$ & $\begin{array}{l}\text { Accuracy } \\
(\%)\end{array}$ \\
\hline $\mathrm{S}_{-}^{\mathrm{e}} \mathrm{F} 2^{\mathrm{f}} \mathrm{OkN}^{\mathrm{g}}$ & 14.0 & 15.3 & 9.3 & - & - & - & - \\
\hline S_F2_24kN & 23.2 & 20.6 & 11.1 & - & - & - & - \\
\hline S_F2_120kN & 44.8 & 42.0 & 6.3 & - & - & - & - \\
\hline S_F4_24kN & 41.7 & 36.4 & 12.8 & - & - & - & - \\
\hline W2_F2_24kN & 25.7 & 20.6 & 19.7 & 17.8 & 30.7 & 21.1 & 18.0 \\
\hline W2_F4_24kN & 37.7 & 36.4 & 3.5 & 17.8 & 52.7 & 36.8 & 2.4 \\
\hline W4_F4_24kN & 35.3 & 36.4 & 3.0 & 33.0 & 6.6 & 36.8 & 4.2 \\
\hline
\end{tabular}

\footnotetext{
${ }^{\text {a }}$ Calculated by Eq. 2

${ }^{\mathrm{b}}$ |testedvalue - predictedvalue|/testedvalue $\times 100$

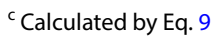

${ }^{\mathrm{d}}$ Calculated by Eq. 10

e Wall configurations: $\mathrm{S}=$ single wall, W2 = two-wall panels connected by 2 connectors, W4=two-wall panels connected by 4 connectors

${ }^{f}$ The number of wall-to-floor connectors: $F 2$ = two connectors, F4 = four connectors

${ }^{g}$ Applied vertical load on top of shear wall specimens
} 


$$
\tan \theta_{\text {max _coupled }}=\frac{\Delta h_{\text {max_coupled }}}{h}=\frac{\delta_{T_{-} \max }}{x_{p 2, \text { furthest }}-\frac{w}{2}}=\frac{17}{(1060-600)} \approx 0.037
$$

where $\tan \theta_{\text {max coupled }}=$ maximum rotation angle of shear wall in coupled-panel kinematic model, $\Delta h_{\text {max_coupled }}=$ lateral displacement on top of shear wall in coupled-panel kinematic model (mm). happened at the connectors on panel 1 due to the displacement between panel 1 and panel $2(\mathrm{~mm})$. Thus, the predicted values by the single-coupled-panel model were higher than those by the single-wall model.

$$
\tan \theta_{\text {max_single-coupled }}=\frac{\Delta h_{\text {max_single }}}{h}=\frac{\delta_{\mathrm{T}_{\text {_max }}}}{x_{\mathrm{p} 1, \mathrm{furthest}}}=\frac{17}{430} \approx 0.039,
$$

where $\tan \theta_{\max \_ \text {single-coupled }}=$ maximum rotation angle of shear wall in single-coupled-panel kinematic model, $\Delta h_{\text {max_single }}=$ lateral displacement on top of shear wall in single-coupled-panel kinematic model $(\mathrm{mm})$, $x_{\mathrm{p} 1 \text {,furthest }}=$ distance of furthest connector on panel 1 from rotation point $(\mathrm{mm})$.

In case of single-wall model, when the rotation angle reached the maximum, the predicted values were $6.3 \%$ to $12.8 \%$ lower than tested data except for two specimens, S_F2_0kN and W4-F4-24kN. The over-estimated range of the two specimens ( $3 \%$ to $9 \%$ ) was not large and may be acceptable. In case of coupled-panel model, when the rotation angle reached the maximum, all of the predicted value was lower than the tested data or predicted values by single-wall model and single-coupled-panel model. In case of single-coupled-panel model, when the rotation angle reached the maximum, the predicted values were $2.4 \%$ to $18.0 \%$ lower than tested data except for W4-F4$24 \mathrm{kN}$ specimens. Although the actual lateral behavior of shear wall specimens was close to the single-coupledpanel model, the structural engineer would determine the lateral load-carrying resistance with the smallest value of the three predictions for safety. Thus, the tested data shows that there is a safety of $6.6 \%$ to $52.7 \%$ when the design value was determined by the coupled-panel model.

The lateral resistance of shear wall specimens was predicted when the rotation angle of the wall reached its maximum, and the load-displacement curve of the connector was assumed to be elastic-plastic. Thus, in two-wall panels (W2 specimen groups), when the same number of wall-to-floor connectors was used (W2 F4_24kN, W4_F4_24kN), the predicted lateral resistances by single-wall model and by the single-coupled-panel model were the same as $36.4 \mathrm{kN}$ and $36.8 \mathrm{kN}$, respectively. In the single-wall model, the closest connector to the rotation point was not reached the yield strength. However, in the single-coupled-panel model, all connectors reached the yield strength when the maximum rotation angle happened, because more displacement
For the coupled-panel model, if the vertical connectors (Fig. 3b) have the same shear resistances $\left(R_{\mathrm{s}}\right.$ in Fig. $\left.3 \mathrm{~b}\right)$, the reaction force at the rotation point $\left(R_{\mathrm{B}}\right)$ of panel 2 increases as much as the tensile resistance increased by the wall-to-floor connectors of panel 2. Thus, when the same number of wall-to-wall connectors were used (W2 F2_24kN, W2_F4_24kN), the predicted lateral resistance by the coupled-wall model was the same as $17.8 \mathrm{kN}$.

For the coupled-panel model, if the shear resistance of the vertical connector is the same, the reaction force at the rotation point of panel 2 increase as much as tensile resistance increase by the wall-to-floor connectors on panel 2. Thus, when the same number of wall-to-wall connectors was used (W2_F2_24kN, W2_F4_24kN), the two predicted lateral resistances by the coupled-wall model were the same as $17.8 \mathrm{kN}$.

Figure 13 is a graph of the tested and predicted values in Table 4. The seven shear wall specimens was consisted of different combination of wall-to-wall connectors and wall-to-floor connectors. The lateral resistances predicted by the prediction models showed similar trends with the tested value for the shear wall configurations. Although number of connections was different, it is

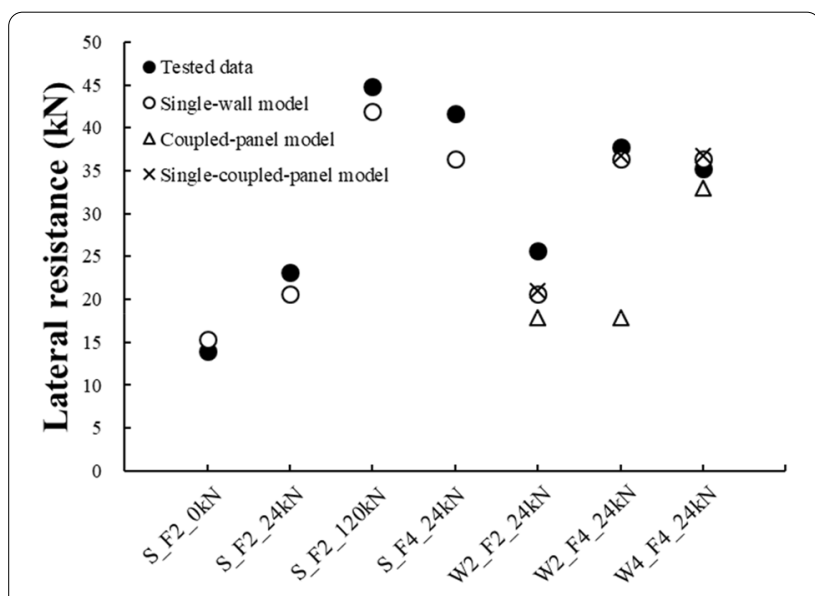

Fig. 13 Comparisons of lateral resistance of shear wall specimens 
shown that the prediction models reasonably predicted the lateral resistance of shear wall specimens by reflecting the mechanical properties and position of connectors. Therefore, the mass timber shear walls consisted of withdrawal-type connectors can be designed by using the kinematic models with the tensile and shear properties of the connectors.

\section{Conclusions}

The aim of this study was to evaluate the lateral performance of Ply-lam shear walls consisting of several withdrawal-type connectors, and to develop a prediction model for shear wall design. The effects of wall-to-wall connector, wall-to-floor connector and vertical loads on the shear wall were investigated by experimental study. As a result, the screws fixing the metal connector to the floor element withdrew in all the test specimens. The number of the wall-to-floor connector affected the shear strength of shear wall rather than the number of the wall-to-wall connector. In case of wall-to-wall connector, even if only two wall-to-wall connectors were used, the separated wall panels showed similar performance to the single-panel wall. As the vertical load increased, all of the mechanical properties for shear wall specimens increased. Thus, the lateral performance of the shear wall specimens was governed by the position of connectors and the vertical load.

Three types of kinematic models to predict the lateral resistance of the shear wall was presented based on the static equilibrium. The load-displacement curves of connector were assumed as an elastic-plastic. The accuracy was $3.0 \%$ to $19.7 \%$ for single-wall model, $6.6 \%$ to $52.7 \%$ for coupled-panel model, and $2.4 \%$ to $18.0 \%$ for singlecoupled-panel model. The lateral behavior of shear wall specimens was close to the single-coupled-panel model. However, the structural engineer would determine the lateral resistance with the smallest value of the three predictions for safety. Therefore, when the lateral resistance of the tested shear wall specimens was determined by the coupled-panel model, tested data show that there is a safety of $6.6 \%$ to $52.7 \%$. In addition, since the lateral resistance of the shear wall is predicted by the lower $5 \%$ performance of the joints, there is a $5 \%$ chance that the performance of the actual shear wall will be overestimated than the predicted value. In addition, except for the absence of vertical loads, all experimental values were higher than the lower of the two predictions. In real buildings, vertical loads always exist, thus, the tested shear wall with vertical loads is close to the actual situation.

\section{Abbreviations}

CLT: Cross-laminated timber; NLT: Nail-laminated timber; MPP: Mass plywood panels; HBF: Harrer GmbH/Frohnleiten; LVDT: Linear variable displacement transducers; EEEP: Equivalent energy elastic-plastic.

\section{Acknowledgements}

1) This study was conducted with the support of the R\&D Program for Forest Science Technology (Project No. 2017049A00-1919-BB02), provided by the Korea Forest Service. 2) This study was conducted with the support of the research project, Development of performance criteria of ecological architecture based on Environmental Product Declaration and modularization construction technology (Project No. 21AUDP-B146511-04), funded by the Ministry of Land, Infrastructure and Transport (MOLIT) and the Korea Agency for Infrastructure Technology Advancement (KAIA).

\section{Authors' contributions}

SJP analyzed the data and wrote this manuscript. KSA designed the experimental setup and performed the experimental test. SGK developed the main material, Ply-lam, and controlled the manufacturing. JKO managed this research. All authors read and approved the final manuscript.

\section{Funding}

This project was funded by the Korea Forest Service (Korea Forestry Promotion Institute) and the Ministry of Land, Infrastructure and Transport (the Korea Agency for Infrastructure Technology Advancement).

\section{Availability of data and materials}

Not applicable.

\section{Declarations}

\section{Competing interests}

The authors declare they have no competing interest.

\section{Author details}

${ }^{1}$ Department of Agriculture, Forestry and Bioresources, Seoul National University, Gwanak-ro 1, Gwanak-gu, Seoul, Republic of Korea. ${ }^{2}$ Department of Bio-Based Materials, Chungnam National University, 99 Daehak-ro, Yuseong-gu, Daejeon, Republic of Korea. ${ }^{3}$ Research Institute of Agriculture and Life Sciences/Department of Agriculture, Forestry and Bioresources, Seoul National University, Gwanak-ro 1, Gwanak-gu, Seoul, South Korea.

Received: 31 December 2020 Accepted: 12 April 2021

Published online: 23 April 2021

\section{References}

1. Tellnes LG, Saxegård SA, Johnsen FM (2020) Cross-laminated timber constructions in a sustainable future-transition to fossil free and carbon capture technologies. IOP Conference Series 588:042060

2. Choi C, Yuk CR, Yoo JC, Park JY, Lee CG, Kang SG (2015) Physical and mechanical properties of cross laminated timber using plywood as core layer. J Korean Wood Sci Tech 43:86-95

3. Choi C, Kojima E, Kim KJ, Yamasaki M, Sasaki Y, Kang SG (2018) Analysis of mechanical properties of cross-laminated Timber (CLT) with plywood using Korean larch. BioResources 13:2715-2726

4. Li Q, Wang Z, Liang Z, Li L, Gong M, Zhou J (2020) Shear properties of hybrid CLT fabricated with lumber and OSB. Constr Build Mater 261:120504

5. Wang Z, Gong M, Chui YH (2015) Mechanical properties of laminated strand lumber and hybrid cross-laminated timber. Constr Build Mater 101:622-627

6. Aicher S, Hirsch M, Christian Z (2016) Hybrid cross-laminated timber plates with beech wood cross-layers. Constr Build Mater 124:1007-1018 
7. Park JH, Kang Y, Lee J, Chang SJ, Wi S, Kim S (2019) Development of wood-lime boards as building materials improving thermal and moisture performance based on hygrothermal behavior evaluation. Constr Build Mater 204:576-585

8. Chang SJ, Wi S, Kim S (2019) Thermal bridging analysis of connections in cross-laminated timber buildings based on ISO 10211. Constr Build Mater 213:709-722

9. Chang SJ, Wi S, Kang SG, Kim S (2020) Moisture risk assessment of cross-laminated timber walls: perspectives on climate conditions and water vapor resistance performance of building materials. Build Environ 168:106502

10. Chang SJ, Wi S, Lee J, Lee H, Cho H, Kim S (2017) Analysis of cooling and heating energy demands of wooden houses with cross-laminated Timber (CLT) using domestic plywood as core materials. J Korean Soc Living Environ Sys 24(6):752-759

11. Pang SJ, Lee HJ, Yang SM, Kang SG, Oh JK (2019) Moment and shear capacity of Ply-lam composed with plywood and structural timber under out-of-plane bending. J Wood Sci 65:1-10

12. Pang SJ, Ahn KS, Kang SG, Oh JK (2020) Prediction of withdrawal resistance for a screw in hybrid cross-laminated timber. J Wood Sci 66:1-11

13. Oh JK, Hong JP, Kim CK, Pang SJ, Lee SJ, Lee JJ (2017) Shear behavior of cross-laminated timber wall consisting of small panels. J Wood Sci 63:45-55

14. Ceccotti A (2008) New technologies for construction of medium-rise buildings in seismic regions: the XLAM case. Struct Eng Int 18(2):156-165

15. Ceccotti A, Sandhaas C, Okabe M, Yasumura M, Minowa C, Kawai N (2013) SOFIE project-3D shaking table test on a seven-storey full-scale crosslaminated timber building. Earthq Eng Struct D 42:2003-2021

16. Dujic B, Pucelj J, Zarnic R (2004) Testing of racking behavior of massive wooden wall panels. In: Proceedings of the 37th CIB-W18 Meeting, Edinburgh, Scotland, Paper 37-15-2

17. Gavric I, Fragiacomo M, Ceccotti A (2015) Cyclic behavior of CLT wall systems: experimental tests and analytical prediction models. J Struct Eng ASCE 141:04015034

18. Gavric I, Fragiacomo M, Popovski M, Ceccotti A (2014) Behavior of cross-laminated timber panels under cyclic loads. Mater Jt Timber Struct 9:689-702

19. Popovski M, Schneider J, Schweinsteiger M (2010) Lateral load resistance of cross-laminated wood panels. In: Proceedings of the 2010 World Conf. on Timber Engineering, Riva del Garda, Italy, Paper 171

20. Canadian Wood Council (2017) Wood Design Manual 2017 (CSA O86). Ontario, Canadian Standards Association, Ottawa, p 1076
21. Morrell I, Soti R, Miyamoto B, Sinha A (2020) Experimental investigation of base conditions affecting seismic performance of mass plywood panel shear walls. J Struct Eng 146:04020149

22. Tamagnone G, Rinaldin G, Fragiacomo M (2020) Influence of the floor diaphragm on the rocking behavior of clt walls. J Struct Eng 146:04020010

23. Casagrande D, Doudak G, Mauro L, Polastri A (2018) Analytical approach to establishing the elastic behavior of multipanel CLT shear walls subjected to lateral loads. J Struct Eng 144:04017193

24. Nolet V, Casagrande D, Doudak G (2019) Multipanel CLT shearwalls: an analytical methodology to predict the elastic-plastic behaviour. Eng Struct 179:640-654

25. ETA 18/0083 (2018) SHERPA CLT-Connector. Austrian Institute of Construction Engineering. Vienna, Austria

26. Flatscher G, Schickhofer G (2016) Displacement-based determination of laterally loaded Cross Laminated Timber (CLT) wall systems. In: Proceedings of the 3rd INTER Meeting, Graz, Austria, August 2016. Paper INTER/49-12-1

27. NIFoS notification No. 2018-8 (2018) Standard and specification of wood products - structural lumber. National Institute of Forest Science, Seoul, Republic of Korea

28. Gagnon S, Pirvu C (2011) CLT handbook: cross-laminated timber. FPInnovations, Quebec, Canada. Chapter 4, p.7

29. Karacabeyli E, Douglas B (2013) CLT handbook: cross-laminated timber US edition, FPInnovations, Pointe-Claire, Canada. Chapter 4, p.27

30. ASTM E 2126-11 (2011) Standard test methods for cyclic (reversed) load test for shear resistance of walls for buildings. American Society for testing and Materials, West Conshohocken

31. HBF Report (2018) Tests on SHERPA CLT-Connectors applied to Ply-lam elements, November 2018, Holz.bau forschungs gmbh, TU Graz, Austria

32. BS EN 26891 (1991) Timber structures. Joints made with mechanical fasteners general principles for the determination of strength and deformation characteristics. BSI Standards Publication, London, UK

33. BS EN 14358 (2006) Timber structures - Calculation of characteristic 5-percentile values and acceptance criteria for a sample. BSI Standards Publication, London, UK

\section{Publisher's Note}

Springer Nature remains neutral with regard to jurisdictional claims in published maps and institutional affiliations.

\section{Submit your manuscript to a SpringerOpen ${ }^{\circ}$ journal and benefit from:}

- Convenient online submission

- Rigorous peer review

- Open access: articles freely available online

- High visibility within the field

- Retaining the copyright to your article

Submit your next manuscript at springeropen.com 